Review Article

\title{
The Advancement of Neutron Shielding Materials for the Storage of Spent Nuclear Fuel
}

\author{
Xuelong Fu $\mathbb{D}^{1},{ }^{1,2}$ Zhengbo Ji $\left(\mathbb{D},{ }^{1}\right.$ Wei Lin, ${ }^{1}$ Yunfeng Yu, ${ }^{1}$ and Tao Wu ${ }^{1}$ \\ ${ }^{1}$ Department of Mechanical and Electronic Engineering, Jiangsu Vocational and Technical College of Finance and Economics, \\ Huai'an, Jiangsu 223003, China \\ ${ }^{2}$ College of Material Science and Technology, Nanjing University of Aeronautics and Astronautics, Nanjing 211106, China
}

Correspondence should be addressed to Xuelong Fu; 308851010@qq.com

Received 10 January 2021; Accepted 1 May 2021; Published 7 May 2021

Academic Editor: Alexander Zulauf

Copyright ( $\odot 2021$ Xuelong Fu et al. This is an open access article distributed under the Creative Commons Attribution License, which permits unrestricted use, distribution, and reproduction in any medium, provided the original work is properly cited.

With the development of nuclear industry, spent nuclear fuel (SNF) generated from nuclear power plants arouses people's attention as a result of its high radioactivity, and how to guarantee the reliable operation of nuclear facilities and the staff's safety occupies a crucial position. To avoid the lethal irradiation, a lot of functional neutron shielding composites have been developed to transform fast neutrons into thermal neutrons which can be absorbed with high macroscopic cross-sectional elements. Irradiation characteristics of nuclear industry have promoted the advancement of neutron shielding materials. Here, we review the latest neutron shielding materials for the storage of spent nuclear fuel containing additives such as boron carbide $\left(\mathrm{B}_{4} \mathrm{C}\right)$, boron nitride (BN), boric acid $\left(\mathrm{H}_{3} \mathrm{BO}_{3}\right)$, and colemanite. Different types of neutron shielding materials, including metal matrix alloys, polymer composites, high density concrete, heavy metals, paraffin, and other neutron shielding composites with high macroscopic crosssectional elements, arediscussed. The elemental composition, density, and thermal and mechanical properties of neutron shielding materials are also summarized and compared.

\section{Introduction}

Traditional coal-based energy structure has caused environmental pollution and ecological destruction, while the energy and environmental problems have become the greatest social and economic constraints of sustainable development [1]. More attention has been paid to clean energy, such as nuclear energy, which embodies huge amount of energy. Although nuclear power could not yield greenhouse gas emissions after taking the environmental protection into consideration, it creates its own waste-spent nuclear fuel with high level radioactivity and generates the particle emissions or high-energy electromagnetic waves. About 437 nuclear power units are in operation around the world, with total installed capacity of 377 gigawatts. These nuclear power plants have generated 3.5 million tons of radioactive wastes, yet still engendering 10,000 tons annually. Normally, spent nuclear fuel contains different radioactive isotopes, and the half-lives of these radioactive isotopes can last for tens of thousands of years, as shown in Figure 1. Moreover, nuclear waste can generate alpha, beta, gamma, proton, and second gamma particle emissions, accompanied by a lot of neutron emissions [2]. Therefore, it is imperative to promote the research and development of neutron shielding materials to ensure the reliable operation and sustainable development of nuclear industry.

Spent nuclear fuel reprocessing includes once-through fuel cycle and recycling treatment, and it always involves the issue of spent fuel storage, regardless of what kind of posttreatment is used. According to the time schedule, storage mode of the SNF can be classified into wet pool storage, dry cask storage, and geological storage. In most cases, the SNF should be firstly stored in the wet pools for 3-5 years, to take the heat generated by nuclear fuel away and attenuate fast neutrons. While dry cask storage is a safer storage mode, it can transfer radioactive waste from wet pools to on-site dry casks directly. These casks always use passive air cooling and do not need other system to back it 


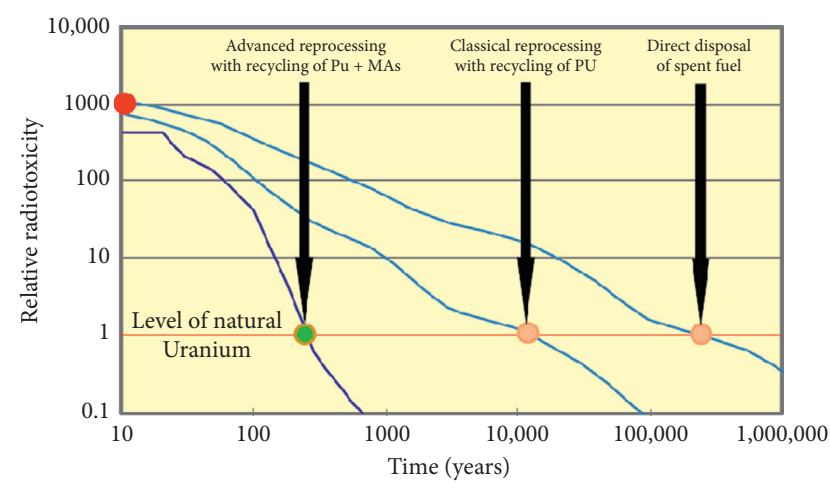

Figure 1: The duration of long-lived spent nuclear fuel [3].

up. Dry cask storage mode can last for decades owing to its superiority. It presents a certain amount of physical and chemical changes occurring in the process of dry cask storage, including irradiation damage and He build-up and migration owing to radioactive substances in the spent nuclear fuel [4]. Normally, neutrons can easily penetrate through a majority of materials and interact with the nuclei of the atom, because neutrons have no electrical charge and can lead to emission of nuclear energy via nuclear fission. This energy can be in ranges and cause lethal damage to human beings and environments. As a result, it must be shielded immediately with the support of neutron shielding materials.

Usually, neutron shielding materials are composed of metals, nonmetals, composite materials, polymer composites, or compounds. Neutron shielding substances always have high macroscopic neutron absorbing cross section, such as boron (B), cadmium (Cd), silver (Ag), indium (In), hafnium (Hf), europium (Eu), gadolinium (Gd), and dysprosium (Dy). Radiation shielding materials and their developments have become the focus of research in order to meet the challenges arising from the requirements of nontoxic, low density, and excellent physical properties. The main objective of this work is to provide the research basis for radiation shielding materials and pave the way for the research directions and application prospect of neutron shielding materials.

\section{Neutron Shielding Mechanism}

The electrically neutral neutrons with strong penetration capabilities are mainly produced by nuclear fission and cannot be easily affected by electrostatic force. According to the energy level, they are usually divided into thermal neutrons $(0.025 \mathrm{eV})$, slow neutrons $(1 \mathrm{keV}-0.025 \mathrm{eV})$, moderate-energy neutrons $(100 \mathrm{keV}-1 \mathrm{keV})$, fast neutrons (100 keV-10 MeV), and high-energy neutrons (energy higher than $10 \mathrm{MeV}$ ). Normally, neutron shielding materials, acting as neutron moderators and neutron absorbers, can alleviate the fast neutrons and absorb the thermal neutrons, as a result lowering the neutron transmission ratio and ensuring the radiation dosage within the safety threshold value. Figure 2 presents the schematic illustration of neutron absorbing mechanism. Neutron shielding materials need to have the effect of neutron shielding performance and neutron irradiation resistance [5]. The main concern of neutron shielding materials concentrates on the planning and designing of component composition, including the heavy elements interacting with fast neutrons via inelastic scattering, light elements acting as a moderator reacting with thermal neutrons via elastic scattering, and boron elements with a high neutron absorption cross section, to attain the purpose of neutron shielding via the synergistic reaction of these substances.

On the other hand, radiation resistance of neutron shielding materials is determined by the relative density, microstructure, vacancies, and interstitial defects inside [6]. Usually, neutron irradiation damage generates the vacancies and interstitial atoms, and the interstitial atoms move quickly to the surface of materials, resulting in volume swelling and causing the appearance of vacancies. In addition, these defects are inclined to aggregate and bring greater resistance to dislocation movement, causing the hardening and embrittlement of neutron shielding materials. He built-up bubbles are generated at grain boundaries or their vicinity in the material. The movement of interstitial defects generated by neutron irradiation causes the swelling of neutron shielding materials and the interface structure evolution of interstitial defects in a nanostructured material, as shown in Figure 3. Moreover, researchers pay attention to simulation analysis as a complement to experiments to explore the behavior of materials at atomic level.

\section{Materials and Properties}

Neutron absorbers are used to control the criticality of spent nuclear fuel storage systems, including borated stainless steel, $\mathrm{B}_{4} \mathrm{C} / \mathrm{Al}$ composite, amorphous alloys, and $\mathrm{B} / \mathrm{Al}$ alloy. Neutron shielding materials contain polymer-based composites, high density concrete, heavy metals, paraffin, and other neutron shielding materials with additives, such as hexagonal boron nitride $(\mathrm{h}-\mathrm{BN})$, boron carbide $\left(\mathrm{B}_{4} \mathrm{C}\right)$, boric acid, colemanite, cadmium (Cd), gadolinium (Gd), and samarium oxide $\left(\mathrm{Sm}_{2} \mathrm{O}_{3}\right)$ fillers. The shielding materials present the good neutron shielding performance efficiently, and the neutrons can be effectively shielded via elastic and inelastic scattering.

\subsection{Neutron Absorbers}

3.1.1. Borated Stainless Steel. Borated stainless steels contain a certain amount of natural or enriched boron ( 0.20 to $2.25 \mathrm{wt} \%)$. Because boron (B) is recognized as an effective thermal neutron shielding element, borated stainless steels with limited fraction of boron element have been broadly applied in the nuclear engineering field for decades [8]. High boron-containing steel, especially borated stainless steel with boron content ranging from $1 \%$ to $2 \%$, is one of the largest consumed radiation protection material. It has excellent fast neutron moderating properties, thermal neutron absorption properties, gamma ray shielding performance, combined with excellent physical properties. Nevertheless, excessive addition of boron will cause the formation of fragile phase 

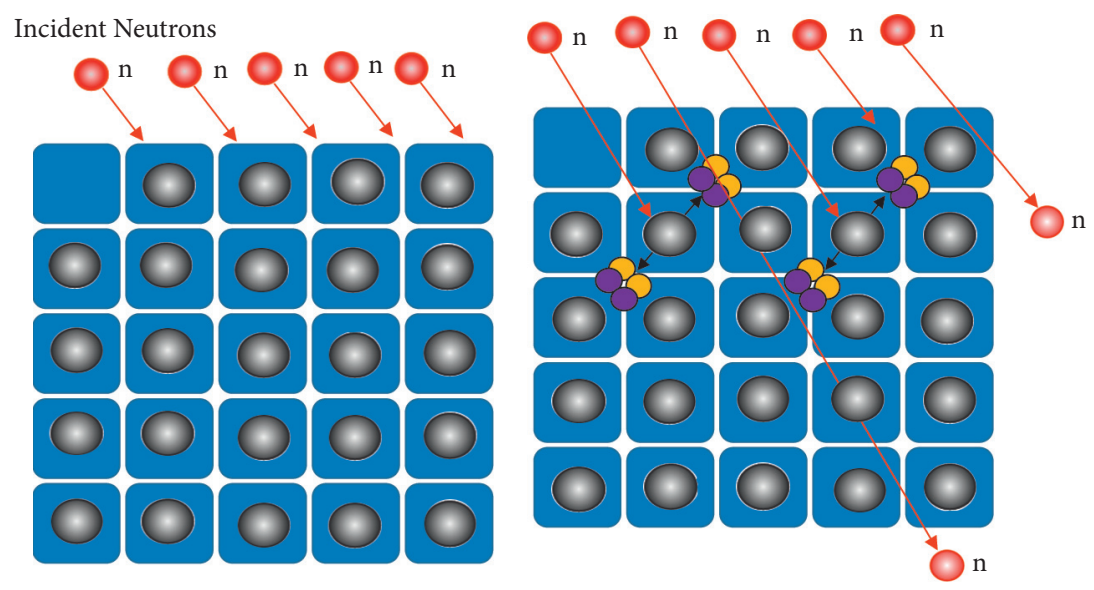

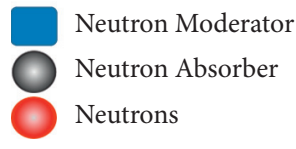

(a)
Neutron Moderator

Neutron Absorber

Neutrons

(b)

FIGURE 2: Schematic illustration of neutron shielding materials: (a) distribution of neutron absorbing elements; (b) neutron absorption process.

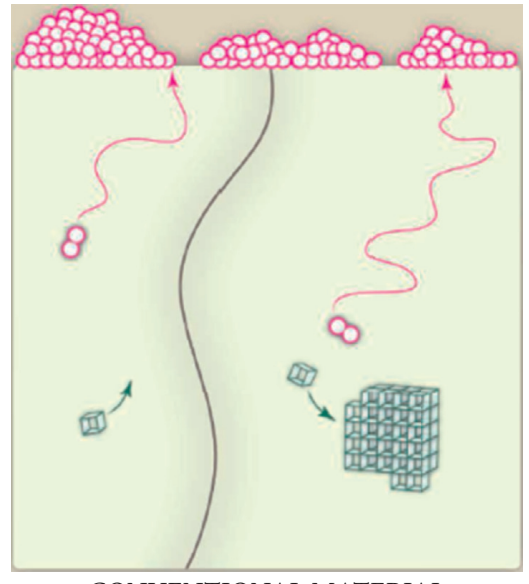

CONVENTIONAL MATERIAL

Self-interstitial

[1] Vacancy

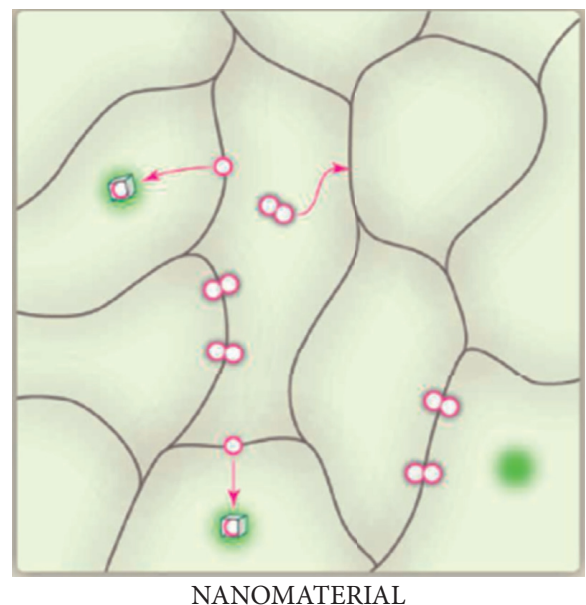

Self-interstitial

Virtual interstitial

Healed crystal

(a)

(b)

Figure 3: (a) The movement of interstitial defects caused by irradiation causing swelling; (b) interface structure evolution of the interstitial defects in a nanostructured material [7].

$(\mathrm{Fe}, \mathrm{Cr})_{2} \mathrm{~B}$, resulting in much lower thermal ductility and increasing the difficulty of the preparation of borated stainless steel, owing to the low solubility limits of boron in the borated stainless steel. On the other hand, excessive addition of boron element causes the degradation of corrosion resistance associated with boride formation [9] and decreases the mechanical properties such as thermal ductility, plasticity, toughness, and machinability. It is necessary to consider the microstructure, mechanical properties, and neutron shielding performance of borated stainless steel [10] and the effects of secondary irradiation on the neutron transmission ratio, causing variations in the internal structure of stainless steels [11]. Figure 4 illustrates the relationship between effective multiplication factor $\left(K_{\text {eff }}\right)$ and boron content and schematic representation of the microstructure based on the MCNP simulation. Furthermore, thermal stability and microstructure variations of borated stainless steel have been evaluated, such as aging 


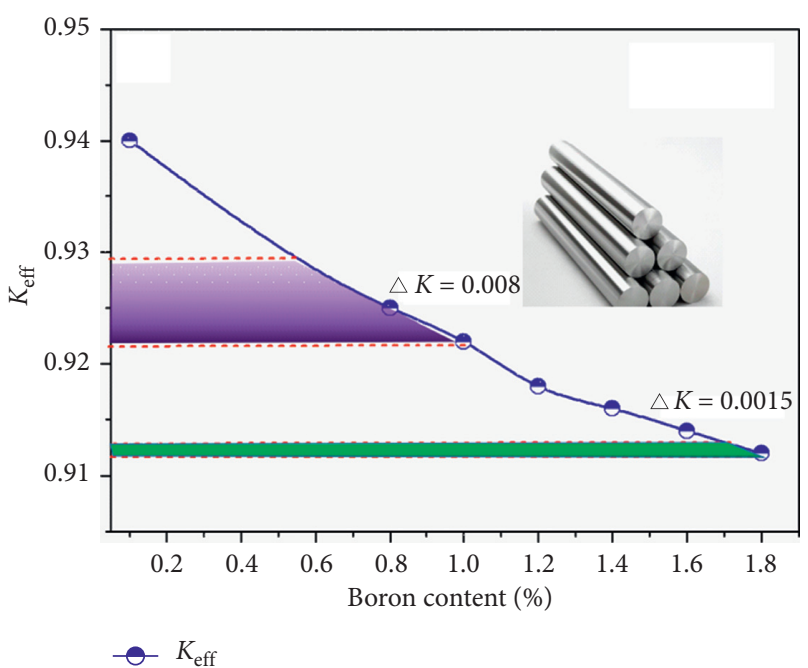

(a)

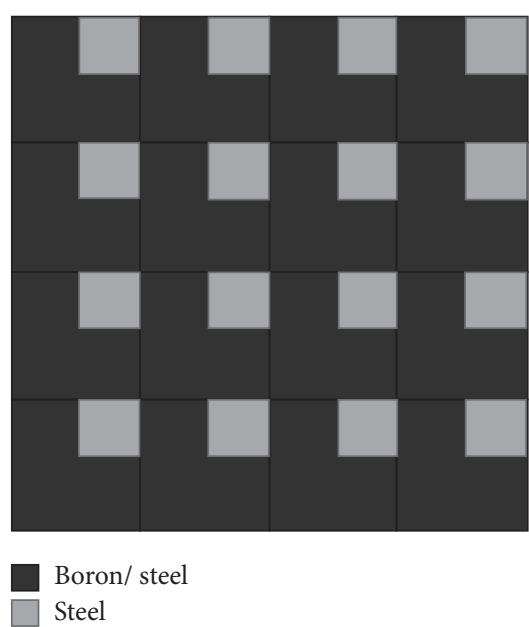

(b)

Figure 4: (a) The relationship between effective multiplication factor and boron content; (b)schematic representation of the microstructure based on the MCNP simulations.

effects on the mechanical properties of stainless steel, differential thermal analysis, and low speed impact measurements [12]. Besides, the effects of aging at various temperatures on the variation of grain size are also examined. The formability and weldability of borated stainless steel are also probed to improve the ductility of welded joint, in order to broaden the usage of borated stainless steel in the field of nuclear engineering [13]. The main concern is how to improve or eliminate the network structure so as to obtain the uniform distribution of boride layer and promote the high wear resistance of boron-containing materials, which is also the main concern of high borated stainless steel investigation. Further studies on helium formation and its formation mechanism under irradiation conditions are still ongoing.

3.1.2. $\mathrm{B}_{4} \mathrm{C} / \mathrm{Al}$ Composite. $\mathrm{B}_{4} \mathrm{C} / \mathrm{Al}$ composite, composed of uniform distribution of $\mathrm{B}_{4} \mathrm{C}$ particles in the aluminum matrix, is one of the most widely investigated materials in the engineering field [14]. The microstructure, mechanical properties, and neutron attenuation performance of $\mathrm{B}_{4} \mathrm{C} / \mathrm{Al}$ composite reinforced with micro-/nanoparticles are widely studied, and its preparation methodologies include vacuum hot pressing followed by hot rolling [15], mechanical alloying method followed by hot press molding [16] or spark plasma sintering (SPS) [17], and stir casting technique followed by cold extrusion [18]. The effects of $\mathrm{B}_{4} \mathrm{C}$ content on the microstructure and mechanical properties of $\mathrm{B}_{4} \mathrm{C} / \mathrm{Al}$ composite are systematically investigated. However, severe interfacial reaction between $\mathrm{Al}$ and $\mathrm{B}_{4} \mathrm{C}$ particles occurs at the interface, and the byproducts presented are inclined to aggregate, resulting in the nonuniform distribution of boron and the deterioration of mechanical properties of composite materials, as presented in Figure 5. Normally, it is necessary to add a certain amount of titanium (Ti) in the metal smelting process to reduce the degree of interfacial reaction.
In order to decrease the secondary gamma ray irradiation, a novel neutron shielding $\mathrm{B}_{4} \mathrm{C} / \mathrm{Al}$ composite containing gadolinium $(\mathrm{Gd}) \quad\left(\left(15 \% \mathrm{~B}_{4} \mathrm{C}+1 \% \mathrm{Gd}\right) / \mathrm{Al}\right)$ prepared by vacuum hot pressing has been developed [19]. Macroscopic transmission cross section $(\Sigma)$ of $\left(15 \% \mathrm{~B}_{4} \mathrm{C}+1 \% \mathrm{Gd}\right) / \mathrm{Al}$ composite is as high as $21.3 \mathrm{~cm}^{-1}$, and the addition of $\mathrm{Gd}$ can replace a part of $\mathrm{B}_{4} \mathrm{C}$ content in the composite, which can increase the plasticity of the composite and maintain the neutron shielding performance simultaneously.

3.1.3. Carbon Nanotubes (CNTs). Some other studies concern the effects of carbon nanotube (CNT) on the mechanical and neutron irradiation performance of aluminum matrix composite, owing to the excellent irradiation resistance of CNT. The relative mechanical and thermal properties of $\mathrm{B}_{4} \mathrm{C} / \mathrm{CNT}$ composites via hot molding process are experimentally investigated while aluminum is used as an additive [20], and the effects of CNT content on the thermal and mechanical properties of $\mathrm{B}_{4} \mathrm{C} / \mathrm{CNT}$ composites are also evaluated with the duration of neutron irradiation damage. Furthermore, the dispersion of CNTs in aluminum is probed to improve their radiation resistance [21]. The tensile properties of $0.5 \mathrm{wt} \% \mathrm{Al} / \mathrm{CNT}$ composite are improved while tensile ductility of the materials is not seriously affected after radiation, decreasing the volume fraction of void/pore at high displacements per atom (DPA). Irradiation damage can generate the accumulated outgas of helium and other fission gases and provide the guidance for gas accumulation problem. Figure 6 presents the schematic illustration of shape changes on CNT, recombination, and helium outgas. Under the ion irradiation, the disintegration of CNT and formation of aluminum carbide from high-energy ion, and restructuring to helical CNT structure from low energy ion are indicated. Figure 7 exhibits the fabrication process and the microstructure and mechanical properties of $\mathrm{Al} / \mathrm{CNT}$ composites, and the testing results prove that the dispersion 


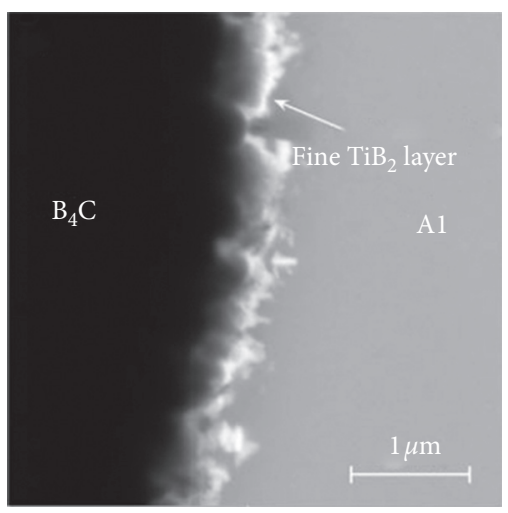

(a)

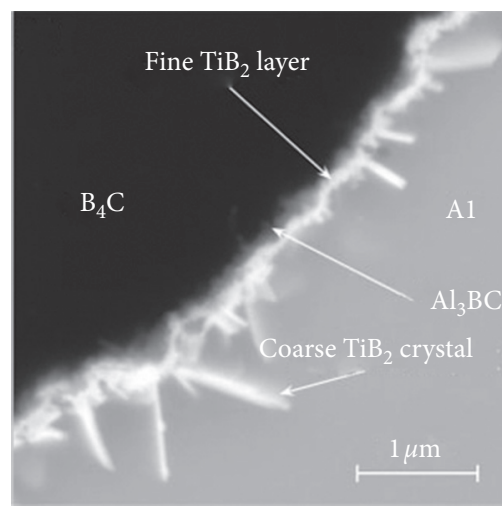

(b)

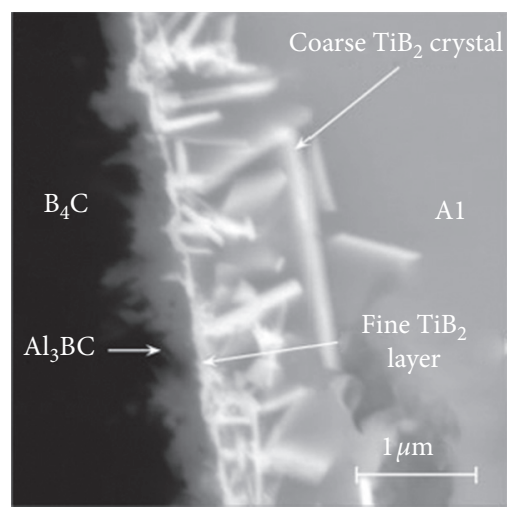

(c)

FIgURE 5: High magnification images of interface microstructure in $\mathrm{B}_{4} \mathrm{C} / \mathrm{Al}$ composites with different stirring time: (a) 5 min; (b) 20 min; (c) $55 \mathrm{~min}[18]$.

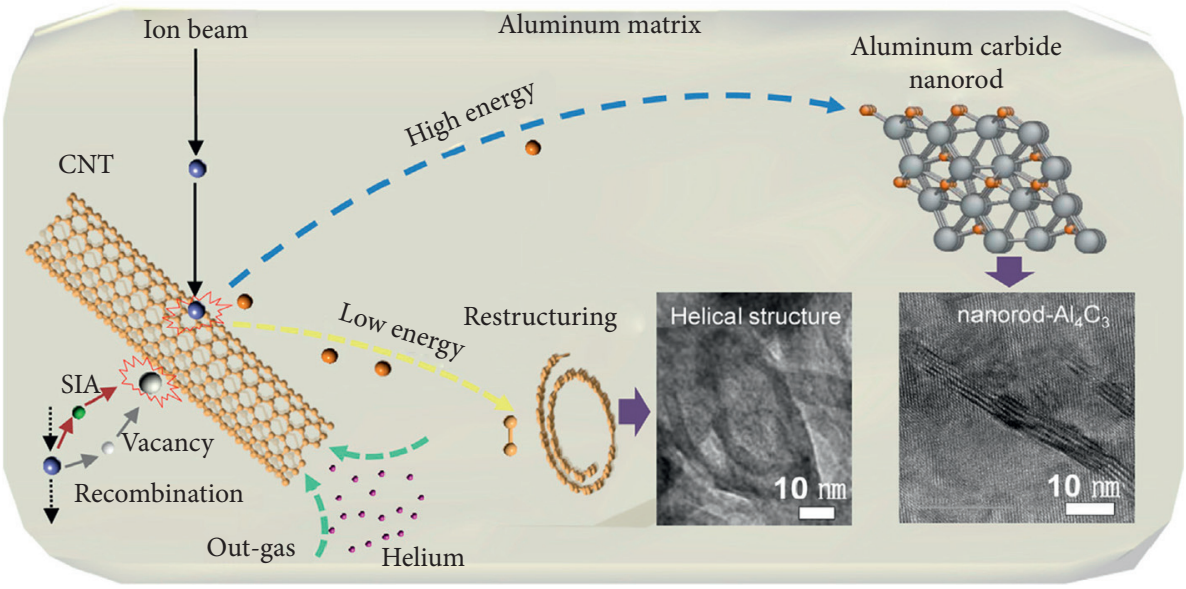

FIGURE 6: Schematic illustration of shape changes on CNT, recombination, and helium outgas [21].

of CNTs in grain improves the tensile strength without sacrificing the ductility.

Additionally, helium behavior, bubble formation, and its evolution in the process of neutron irradiated that $\mathrm{B}_{4} \mathrm{C} / \mathrm{Al}$ composite is deeply investigated [22], and the results reveal that helium bubbles in $\mathrm{Al}$ matrix are so much larger when compared with $\mathrm{B}_{4} \mathrm{C}$ reinforcements after the irradiation of helium ion with the intensity of $1.5 \times 10^{17}$ ions $/ \mathrm{cm}^{2}$; besides, bubbles generated at the interface or nearby are oriented. With the irradiation of proton, the bubble zone appears along the matrix grain boundary. The microstructure evolution of $15 \mathrm{wt} \% \mathrm{~B}_{4} \mathrm{C} / \mathrm{Al}$ composites prepared by liquidstirring process is also probed [23]. Figure 8 presents the neutron transmission of $\mathrm{B}_{4} \mathrm{C} / \mathrm{Al}$ composite with different $\mathrm{B}_{4} \mathrm{C}$ fraction, and $\mathrm{Cd}$ plate with the thickness of $0.5 \mathrm{~mm}$ is taken for comparison.

3.1.4. Amorphous Alloys. Amorphous alloys, acting as thermal absorbing materials, have unique advantages over conventional carbon billets, including the stability of physical and chemical properties and homogeneous distribution of alloying elements, to ensure amorphous alloys with good corrosion resistance and neutron shielding performance $[24,25]$. The amorphous alloys with high fraction of boron elements have been developed for reducing the irradiation dosage of spent nuclear fuel, and the neutron transmission ratio as well as corrosion resistance is also determined [26]. In addition, mechanical properties of amorphous alloys are investigated for practical SNF storage applications to guarantee the safety of nuclear facilities, especially in the storage of spent nuclear fuel with high radioactivity. Amorphous alloys as a thermal spraying coating can be sprayed on the spent nuclear fuel containers. These amorphous alloys have been made to undergo a series of corrosion resistance tests and long-term irradiation damage tests. Moreover, the performance of boron-containing amorphous ribbons $\mathrm{Fe}_{72-x} \mathrm{~B}_{25-x} \mathrm{Mo}_{3} \mathrm{Cr}_{x}$ (where $x=0$, $5,10,15$, or 20 at $\%$ ) for nuclear engineering applications has been analyzed [27]. The testing results suggest that boroncontaining amorphous ribbons with a certain amount of chromium present satisfying neutron shielding performance and good mechanical properties such as tensile properties and flexural properties. Furthermore, corrosion resistance of neutron shielding materials has high requirements to ensure enough lifetime for spent nuclear fuel storage facilities. 


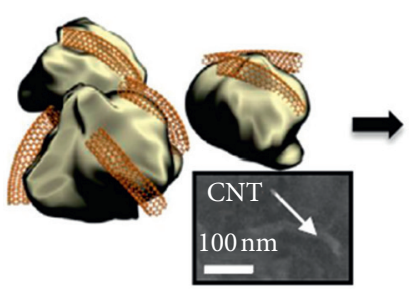

Step i: Declustered CNTs

Al particle

CNT

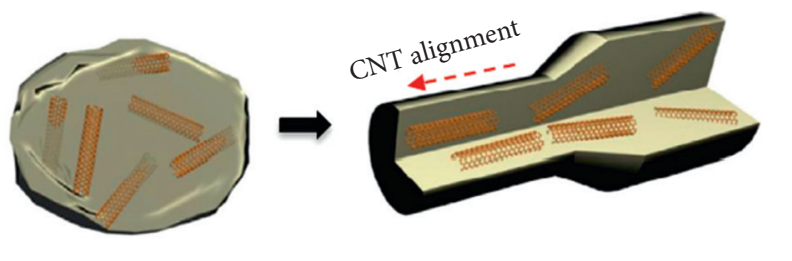

Step ii: Encapsulation \& consolidation

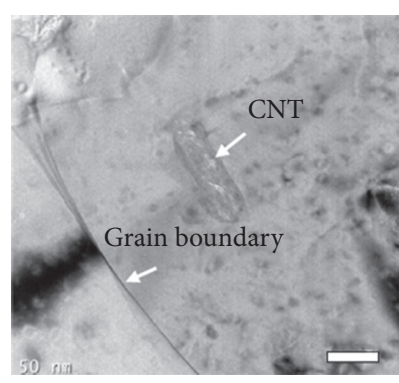

(b) (a)

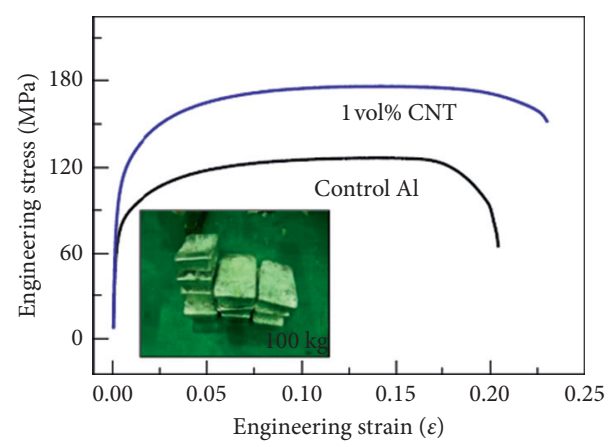

(c)

FIGURE 7: Fabrication process and microstructure/mechanical properties of Al/CNT composites: (a) schematic representation for the preparation of Al/CNT composite; (b) dispersion of CNT inside Al grain in TEM; (c) stress-strain curve [21].

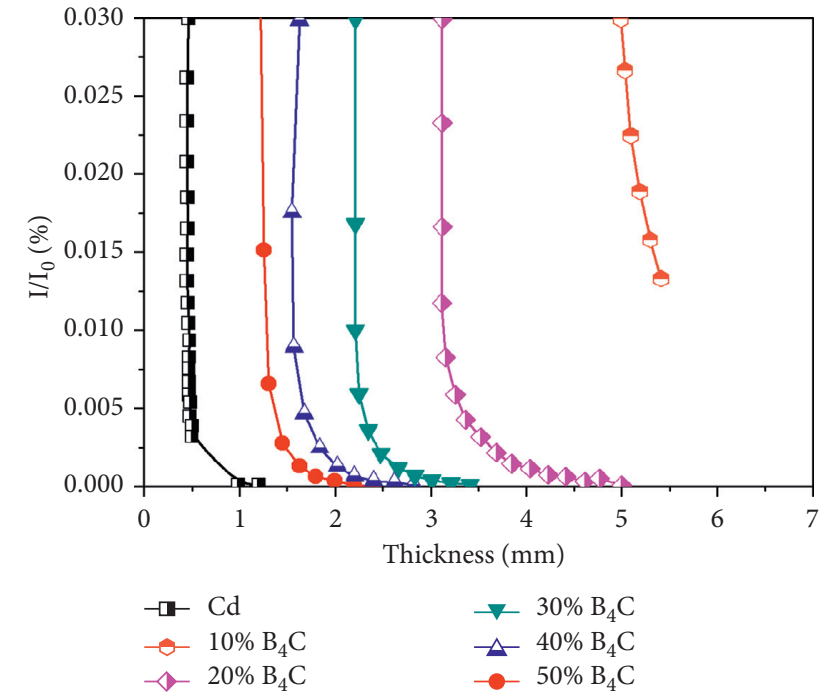

FIGURE 8: Neutron transmission of $\mathrm{B}_{4} \mathrm{C} / \mathrm{Al}$ composite with varying thickness.

Uniform protective layers with a certain amount of $\mathrm{Cr}$ elements can be successfully prepared, and the prepared amorphous alloys have good corrosion resistance, which can be attributed to the homogeneous distribution of $\mathrm{Cr}$ in the amorphous alloys [28, 29].

3.1.5. B/Al Alloy. To some degree, $\mathrm{B} / \mathrm{Al}$ alloy is similar to borated stainless steel, owing to the low solubility of boron in aluminum. Only limited amounts of boron and aluminum react with each other, and the formation of rich borides around the grain boundary increases the brittleness of alloying material. If the neutron absorbing material with limited boron content is used in the spent fuel pool, the critical control of nuclear reaction cannot be guaranteed. Therefore, spent fuel storage materials are usually combined with ${ }^{10} \mathrm{~B}$-enriched neutron to ensure a composite with high ${ }^{10} \mathrm{~B}$ areal density, avoiding the addition of excess boron and the serious deterioration of processing performance of material.

EaglePicher company develops two different neutron absorbing materials, 1100 aluminum alloy and 6351 aluminum alloy, with boron content ranging from $0.5 \%$ to $4.5 \%$ and $0.5 \%$ to $2.5 \%$, respectively [30]. In order to prepare the ingots with a more uniform distribution of boron elements, titanium salt is added with a certain concentration. The $\mathrm{B} / \mathrm{Al}$ alloy has good corrosion resistance in $80^{\circ} \mathrm{C}$ deionized water, while in the aqueous solution of boric acid, there is local pitting corrosion with the $\mathrm{PH}$ value ranging from 4.5 to 6.5 . There is no obvious dimensional change or radiation damage with the neutron dose for dry storage vessel design life of $\mathrm{B} /$ $\mathrm{Al}$ alloy under the neutron irradiation $\left(1 \times 10^{17} \mathrm{nvt}\right)$. Table 1 presents the advantages and disadvantages of neutron shielding metal alloy materials.

3.1.6. Neutron Absorbing Material Containing $C d$ and $G d$ Elements. Cadmium is a soft, malleable, ductile, bluishwhite divalent metal, which is widely used in batteries, electroplating, sensors, pigments, and nuclear engineering. When cadmium elements are applied in the nuclear engineering, it is necessary to add a coating layer such as stainless 
TABle 1: Advantages and disadvantages of neutron shielding metal alloy materials.

\begin{tabular}{|c|c|c|c|}
\hline Materials & $\begin{array}{l}\text { Boron content } \\
\quad(w t \%)\end{array}$ & Advantages & Disadvantages \\
\hline $\begin{array}{l}\text { Borated stainless } \\
\text { steel }\end{array}$ & $0.20-2.25$ & $\begin{array}{l}\text { Irradiation resistance, corrosion resistance, high } \\
\text { temperature resistance }\end{array}$ & Low boron solubility, highly enriched ${ }^{10} \mathrm{~B}$ \\
\hline $\mathrm{B}_{4} \mathrm{C} / \mathrm{Al}$ composite & $<25$ & $\begin{array}{l}\text { Low density, low porosity, good mechanical } \\
\text { properties, corrosion resistance }\end{array}$ & Various effects in the process of manufacturing \\
\hline $\mathrm{B}_{4} \mathrm{C} / \mathrm{Al}$ ceramics & $27.4-50.9$ & Low density, high boron content & $\begin{array}{l}\text { High porosity, poor structure performance, } \\
\text { low corrosion resistance }\end{array}$ \\
\hline $\mathrm{B} / \mathrm{Al}$ alloy & $0.5-4.5$ & Low density, high thermal conductivity & $\begin{array}{c}\text { Low mechanical performance, low boron } \\
\text { solubility }\end{array}$ \\
\hline Amorphous alloy & $<20$ & $\begin{array}{l}\text { Excellent neutron shielding efficiency, high } \\
\text { corrosion resistance }\end{array}$ & $\begin{array}{c}\text { Distribution of alloying elements, interfacial } \\
\text { reaction }\end{array}$ \\
\hline
\end{tabular}

steel owing to its poor strength, high toxicity, and low corrosion resistance. On the other hand, gadolinium (Gd) has two types of isotopes with high neutron absorption cross section, which is also an excellent neutron absorbing material. Such materials can be used as a kind of neutron absorbing materials for long-term spent fuel storage and have been used in Yucca Mountain spent fuel storage facilities. The mechanical properties, weld properties, corrosion resistance, and neutron absorption behavior of $\mathrm{Gd}$ alloys have been studied in Idaho National Laboratory. Nevertheless, the manufacturing of neutron absorbing materials is still in the laboratory stage.

Moreover, the materials containing lithium compounds have been developed as neutron absorbers [31, 32]. The reason lies in the fact that lithium nuclei absorb thermal neutrons via the nonradioactive ${ }^{6} \mathrm{Li}(\mathrm{n}, \mathrm{a}) \mathrm{T}$ reaction. An effective methodology for the preparation of high density $\mathrm{LiF}$ pellets, which is suitable for self-supporting neutron shielding function, has been developed [33].

\subsection{Neutron Shielding Materials}

3.2.1. Polymer-Based Composites. Polymer-based composites are the productive candidates for neutron attenuation as a result of the following reasons. First of all, polymer composites, containing high content of hydrogen elements, have the smallest atomic diameter and can transform fast neutrons into thermal neutrons effectively; second, they are lighter than metal matrix composites, and functional polymer composites can be used as structural materials when combined with micro- or nanoparticles, whiskers, fibers, and tubes. Polymer composites also have reasonable structural, mechanical properties, satisfying radiation shielding properties, etc. [34]. Usually, organic polymer, with high content of hydrogen being the best moderating material, has an obvious effect on the moderation of fast neutrons, and hydrogen atom with the smallest atomic diameter, contained in the polymer composite, is also a desirable case for thermal neutron shielding. To further enhance the neutron shielding performance, boron-containing neutron absorber is usually added to organic polymers. Organic polymers, mainly including high density polyethylene (HDPE) [35], epoxy resin (EP) [36], phenolic resin [37], polyimide resin (PI) [38], and EPDM [39], are commonly used in radiation shielding engineering in the polymer material, while boron-containing materials including $\mathrm{B}_{2} \mathrm{O}_{3}, \mathrm{BN}, \mathrm{B}_{4} \mathrm{C}$, and colemanite are always used as neutron absorbers. It is reported that ${ }^{10} \mathrm{~B}$-containing materials such as boron carbide and boron nitride are excellent neutron absorbers, among which boron nitride is the only available engineering material. Boron nitride nanotubes (BNNTs) are currently very expensive, while boron nitride nanoparticles can be easily obtained from boron nitride powder by sonication centrifugation method. Furthermore, polymer materials enriched with low atomic number elements such as hydrogen proved to be appropriate candidates for neutron shielding.

After the addition of boron-containing materials, boron and hydrogen can capture the thermal neutrons with the emerging of secondary gamma rays and enhance thermal neutron absorption capacity. Polymer-based neutron shielding materials are usually prepared via high speed mixing, kneading, plasticizing, and laminating. The results show that polymer composites have good engineering properties and dimensional stability with satisfactory radiation resistance, which is suitable for engineering applications, with the temperature ranging from $80^{\circ} \mathrm{C}$ to $100^{\circ} \mathrm{C}$. With the increase of irradiation dosage, the testing results demonstrate that the emission gases include $\mathrm{H}_{2}, \mathrm{CO}_{2}, \mathrm{CO}$, and $\mathrm{CH}_{4}$, and the dimension of polymer composite and mass attenuation change significantly. When compared with metal alloy materials, organic polymer neutron absorbing material is more vulnerable to irradiation damage. Longterm irradiation generally reduces the molecular weight of polymer, lowering the softening temperature and increasing the material's solubility to a certain extent.

As one of the most widely used polymers, high density polyethylene (HDPE) has been developed to be applied in the field of neutron shielding engineering, but the obvious drawback of HDPE is its low glass transfer temperature $\left(90^{\circ} \mathrm{C}\right)$. Besides, the thermal neutron capture of hydrogen is accompanied by secondary gamma rays, which can be lethal to human beings. As a result, researchers develop the neutron shielding resin with high temperature resistance, for example, KRAFTON-HB4 $\left(150^{\circ} \mathrm{C}\right)$ [40], containing boron elements to reduce the emission dosage of secondary gamma rays based on the epoxy resin, and EPONITE $\left(200^{\circ} \mathrm{C}\right)$ [41]. 
Recently, boron-containing polymer as a new neutron shielding resin with the heatproof resistance of $300^{\circ} \mathrm{C}$ has been studied [42]. With the increase of boron areal density, neutron shielding performance can be enhanced with the improvement of the collision between thermal neutrons and neutron shielding polymers [43].

(1) $B_{4} C$ or BN/HDPE. High density polyethylene (HDPE) is a very effective neutron shielding thermoplastic polymer and displays excellent attenuation behavior owing to its high hydrogen content ( $14.4 \%$ by weight). It is also the most common polymer used in the neutron shielding engineering. The chemical composition of HDPE is presented in Table 2. Under the irradiation atmosphere, hydrogen elements contained in the HDPE can capture the thermal neutrons via ${ }^{1} \mathrm{H}(n, \gamma){ }^{2} \mathrm{H}$ reaction, with thermal neutron absorbing cross section of 0.33 barn at room temperature. It is always accompanied by emitted $\gamma$-rays with the energy of $2.2 \mathrm{MeV}$. These $\gamma$-rays can affect the physical properties of polymer composite and degrade the mechanical properties of polymer composite at certain situations. On the other hand, fast neutrons can be attenuated when collided with hydrogen elements, and captured by boron elements added to HDPE via ${ }^{10} \mathrm{~B}(n, \alpha){ }^{7} \mathrm{Li}$ reaction [44]. Meanwhile, it is reported that ${ }^{10} \mathrm{~B}$-containing materials such as boron carbide $\left(\mathrm{B}_{4} \mathrm{C}\right)$ and boron nitride $(\mathrm{BN})$ are excellent neutron absorbers by virtue of their huge thermal neutron absorbance [45]. Nevertheless, boron fillers used in these composites suffer from the lack of interfacial adhesion with the HDPE matrix, leading to a limited improvement or even decay of physical and radiation shielding properties of $\mathrm{HDPE} / \mathrm{BN}$ or $\mathrm{B}_{4} \mathrm{C}$ composites [46]. Owing to the poor contact angle between particles and polymers, fillers should be functionalized firstly. Alkoxysilanes, as one of the most widely used materials, can activate the surface of fillers through hydroxyl group. Figure 9 illustrates the effects of (a) $\mathrm{B}_{4} \mathrm{C}$ and (b) silane untreated or treated boron nitride on the tensile strength and elastic modulus of HDPE matrix composite materials.

On the other hand, a Sandwich type of $\mathrm{B}_{4} \mathrm{C}$-based neutron shielding composites reinforced by carbon fiber has been developed [47]. The carbon fiber reinforced $\mathrm{B}_{4} \mathrm{C}$ based neutron shielding composites enhanced not only thermal neutron shielding performance but also mechanical and thermal stability. This was attributed to the appropriate combination of the $\mathrm{B}_{4} \mathrm{C}$ with good radiation shielding property and the carbon fibers with good tensile strength and thermal conductivity. Moreover, the effects of particle size and content of $\mathrm{B}_{4} \mathrm{C}$ particles on the thermal neutron shielding performance of $\mathrm{HDPE} / \mathrm{B}_{4} \mathrm{C}$ composite are also investigated based on the experimental and simulation studies [48]. It can be concluded that mean size of $\mathrm{B}_{4} \mathrm{C}$ particles and their distribution can influence the collision between thermal neutrons and neutron shielding composites, as a result affecting the neutron shielding performance.

Neutron shielding performance of polymer composites, composed of high density polyethylene with different amounts of modified boron carbide, increases with the volume fraction of $\mathrm{B}_{4} \mathrm{C}$ particles in the composite matrix. Nevertheless, the effects of boron carbide and thermal oxidative aging on mechanical properties and swelling of composites in different solvents are also studied in these composites [49].

(2) Epoxy Resin. Epoxy resin presents a variety of forms, accompanied by strong adhesion and high mechanical properties, and it exhibits good chemical stability after curing process. It is always combined with other reinforcements such as fibers, whiskers, and particles. The composite materials are prepared using various methods to form a complicated interplay between reinforcements and polymers, affecting the macroscopic and microscopic morphology, mechanical properties, and durability of polymer-based composite. In the system, macroscopic properties might be degraded depending on the interfacial adhesion between different materials. It has been reported that the mean size, aspect ratio, and content of the reinforcements are the crucial factors affecting the performance of polymer composites [50, 51]. Usually, polymer composites with low concentration of reinforcements exhibit high mechanical properties owing to the unanimous distribution of fillers, but when containing higher fraction of $\mathrm{B}_{4} \mathrm{C}$ particles, deposition and agglomeration in the polymer matrix can be observed, resulting in poor adhesion between $\mathrm{B}_{4} \mathrm{C}$ particles and epoxy resin and lowering the mechanical strength and durability. Consequently, silane coupling agents, combined with ultrasonic dispersion process, have been widely applied to improve the interfacial adhesion between epoxy polymer and fillers and enhance the relative durability. Relevant research illustrates that hydroxyl groups and $\mathrm{B}-\mathrm{O}$ bonds can enhance the interfacial adhesion via the formation of covalent bonds and silane condensation. Uniform dispersion of $\mathrm{B}_{4} \mathrm{C}$ particles and good interfacial adhesion between epoxy resin and $\mathrm{B}_{4} \mathrm{C}$ particles can be observed under the assistance of ultrasonic dispersion technique [36], because unanimous dispersion of fillers in the polymer is crucial for achieving satisfying mechanical properties.

Meanwhile, functional epoxy-based composites with the mixture of $\mathrm{B}_{4} \mathrm{C}, \mathrm{Al}(\mathrm{OH})_{3}$, and $\mathrm{PbO}$ fillers have been prepared using ultrasonic dispersion approach [52]. The results suggest that this dispersion approach guarantees the good wettability between reinforcements and epoxy resin and enhances the interfacial adhesion effectively. With the addition of different fillers to the epoxy resin, a synergistic effect can be created in different materials on condition of ultrasonic dispersion, as a result increasing the relative properties such as mechanical properties, flame retardancy, thermal degradation behavior, and neutron transmission ratio. Besides, molybdenum (Mo) powder is added to epoxy resin in order to enhance the neutron shielding performance of epoxy resin and find out the optimum epoxy-molybdenum ratio [53]. Neutron shielding performance of epoxybased composites is investigated for the optimized epoxy/ Mo composition ratio, when compared with other neutron shielding materials such as stainless steel, paraffin, $\mathrm{B}_{4} \mathrm{C}$ particles, and high density concrete. On the other hand, tensile strength of polymer composite using ultrasonic dispersion process is maintained when compared to the 
TABLE 2: Chemical composition of polymers.

\begin{tabular}{|c|c|c|c|c|c|}
\hline Resin & Polyethylene & KRAFTON-HB4 & Eponite & $300^{\circ} \mathrm{C}$ resin & Developed resin \\
\hline Density $/ \mathrm{g} \cdot \mathrm{cm}^{-3}$ & 0.93 & 1.08 & 1.7 & 1.8 & 1.28 \\
\hline \multicolumn{6}{|l|}{ Element (wt\%) } \\
\hline $\mathrm{H}$ & 14.4 & 10.4 & 25.5 & 29.4 & 8.2 \\
\hline $\mathrm{C}$ & 85.6 & 74.5 & 43.8 & 30.4 & 46.8 \\
\hline $\mathrm{O}$ & & 10.6 & 8.9 & 6.1 & 27.6 \\
\hline B & & 2.0 & 1.2 & 0.31 & 3.4 \\
\hline $\mathrm{N}$ & & 2.13 & & 14 & 2.2 \\
\hline $\mathrm{Si}$ & & 0.38 & & 7.4 & \\
\hline $\mathrm{Ca}$ & & 0.01 & & 6.8 & \\
\hline $\mathrm{Al}$ & & 0.01 & & & \\
\hline
\end{tabular}

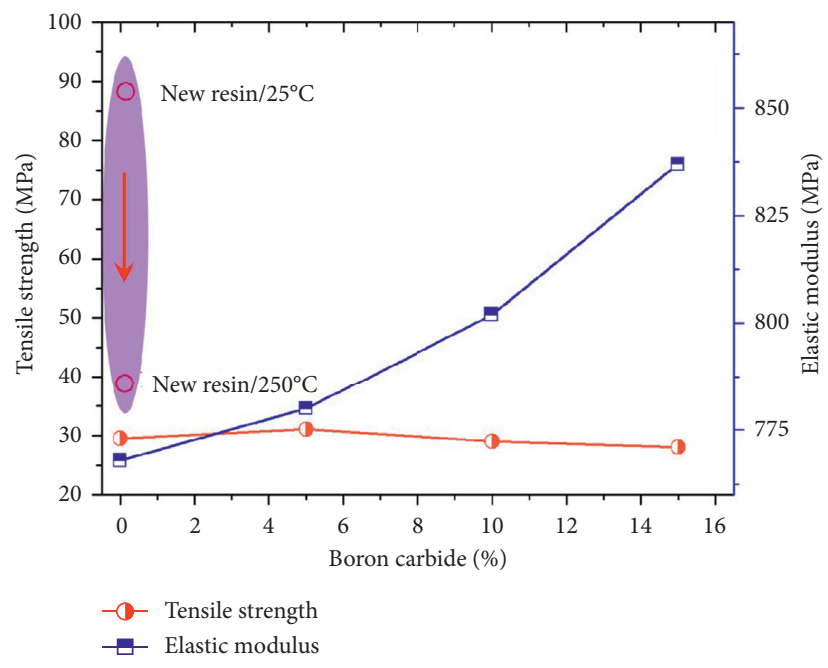

(a)

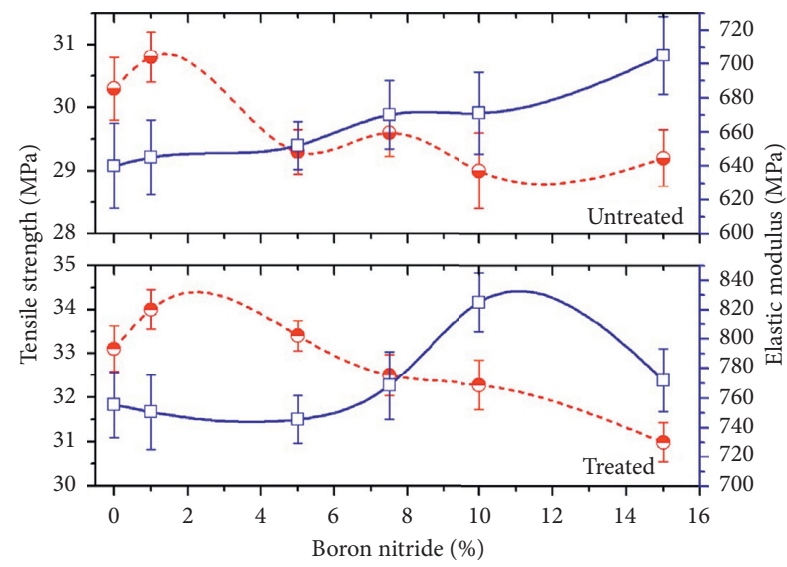

(b)

FIGURE 9: Effects of (a) boron carbide and (b) silane untreated or treated boron nitride on the tensile strength and elastic modulus of HDPE based composite materials.

testing results of neat EP matrix, while the tensile strength decreases obviously for the composite untreated.

(3) Polyimide Resin. As one of the high performance polymers, polyimide (PI) resin is universally known as a result of its excellent thermal stability with temperature up to $400^{\circ} \mathrm{C}$, high irradiation resistance, good chemical stability, adhesive bonding, and electrical insulation properties [54]. Moreover, tensile strength of PI resin without additives exceeds $100 \mathrm{MPa}$, and the tensile strength of PI film reached about $90 \%$ even after $5 \times 10^{7}$ Gy irradiation. A variety of neat polyimide or polyimide-based polymer composites have been developed, and majority of composites are put into use in the electronic or microelectronic component and aviation filed. Some works focus on the preparation of a flexible polyimide film with high electrical insulation and good thermal conductivity, which is composed of functionalized boron nitride (f-BN) and glycidyl methacrylate-grafted graphene (g-TrG) mixed with PI resin [55]. Hexagonal boron nitride (h-BN) reinforced PI-based composite has also been prepared with the mixtures of alkoxysilane functionalized h-BN particles and polyamic acid through a variety of amidization and imidization procedures [56]. On the other hand, polyamide resin has been utilized to prepare the neutron shielding hybrid composite laminates with different configurations $(5 / 4,4 / 3,3 / 2,2 / 1)$ using hot molding process in atmospheric environments, consisting of stacking layers of neutron shielding composite, AA6061 aluminum plates, and carbon fiber reinforced PI composite [57]. The testing results illustrate that neutron shielding performance of hybrid composite laminates decreases obviously with the increasing of the configurations, owing to the enhancement of ${ }^{10} \mathrm{~B}$ areal density in the composite laminates. The effects of carbon fibers on the neutron shielding performance of composite laminates are also taken into consideration. The application prospect of polyimide resin is promising, and it can be used at elevated temperature owing to its high temperature. Some researchers have investigated heat resistant boron-loaded resin with temperature of $300^{\circ} \mathrm{C}$ for neutron shielding to satisfy the application requirement.

(4) Ethylene Propylene Diene Monomer (EPDM). As one of the synthetic resins, EPDM rubber is a good candidate for neutron shielding engineering owing to its high hydrogen fraction. It has outstanding radiation stability after gamma 
irradiation with the dosage of $1.178 \mathrm{kGy}$, and it is a potential polymeric material as a matrix mixed with neutron absorber for neutron shielding function. Özdemir et al. [39] have prepared the EPDM rubber mixed with boric acid to take it as neutron moderator and absorber, and its vulcanization kinetics has also been probed so as to deeply understand the vulcanization behavior with the addition of boric acid. On the other hand, flexible EPDM rubber with boron trioxide is investigated, and its thermal, mechanical, and neutron shielding properties are also examined [58]. The testing results illustrate that flexible composite acting as an effective neutron shielding material has satisfied the requirements of advanced composite.

Moreover, some studies determine the neutron shielding behavior of EPDM rubber embedded with lead filler using Monte Carlo simulation [59] and probe the thermal and mechanical properties of electron beam irradiated HDPE/ EPDM blends in the presence of triallyl cyanurate [60]. The effects of fillers content on the mechanical properties and neutron shielding performance are estimated, after considering the variation of energy by means of energy dissipation.

3.2.2. Concrete. Concrete is one of the most widely used materials to shield gamma ray and neutrons in nuclear installations, and it can be easily molded into complex shape with low cost for construction and maintenance. Concrete has good structure performance and is suitable for neutron and proton shielding when compared with other shielding substances [61]. Depending on the shielding requirement, various types of concrete with different densities and combinations are being used. Radiation attenuation in concrete mainly lies in the types of aggregate, water-cement ratio, elemental composition, and moisture content apart from the density of concrete. Moreover, operating temperature plays a vital role in deciding the neutron shielding properties as a result of the loss of water content and microcracking [62]. On the other hand, polymer concrete such as glass-polymer-concrete ternary hybrid composites, composed of ternary blended concrete with glass waste and polymer as reinforcement and binder, is studied [63], and the relative chemical, thermal, and mechanical properties are investigated. The compressive strength relating to ages increases up to the maximum value of $52.43 \mathrm{MPa}$ at the ratio of $10 \%$ and $8 \%$ by mass of glass powder and polymer, respectively, while thermal conductivity for the optimum specimen is $0.73 \mathrm{~W} / \mathrm{m} \cdot \mathrm{K}$ compared to the conventional one $(1.2 \mathrm{~W} / \mathrm{m} \cdot \mathrm{K})$. Concrete with the addition of boron carbide as fine aggregates is prepared to test the attenuation properties by getting the attenuation coefficient of concrete/ $\mathrm{B}_{4} \mathrm{C}$ [64]. It was indicated that attenuation coefficient of the specimen with $20 \mathrm{wt} \%$ of $\mathrm{B}_{4} \mathrm{C}$ is $0.299 \mathrm{~cm}^{-1}$, while that of the sample without $\mathrm{B}_{4} \mathrm{C}$ is $0.238 \mathrm{~cm}^{-1}$.

On the other hand, novel high density magnetite concrete with different configurations has been developed as an effective neutron shielding material [65], and neutron shielding performance of this low activation concrete is measured to ensure high density concrete with optimum shielding efficiency. When compared with ordinary concrete, high density magnetite concrete exhibits an obvious advantage, making it more competitive. In addition, WinXCom and NXcom programs are being used to investigate the gamma rays and neutrons shielding of twelve concrete samples with or without mineral additives, in order to reduce the difficulty and increase the efficiency [66]. The linear attenuation coefficients, total mass attenuation, halfvalue thicknesses, effective atomic numbers, and atomic cross-sections with different photon energies have been tested and calculated.

3.2.3. Heavy Metals. Neutron shielding efficiency of heavy metals is correlated with the types of radiation source and its energy level. Heavy metals such as lead oxide, bismuth, barium, and other high atomic number materials have been prepared to attenuate the lethal radiation rays. At present, various types of heavy metal oxide glasses, including bismuth borosilicate glasses [67], binary bismuth silicate glasses [68], and silicate and borated heavy metal oxide glasses [69], have been developed to replace the lead-based glasses with satisfying neutron shielding performance. Actually, high atomic number materials cannot block or absorb all types of radiations emitted from nuclear radiation sources, especially the emission radiation from nuclear laboratories. Usually, the radioactive shielding instruments made from lead oxide and composites of lead oxide/tungsten/tin for attenuation or absorption of undesired radiations are heavy and bulky, which is not consistent with the requirements of lightweight materials in the applications. With the development of nuclear engineering, the demand for novel shielding materials has increased to apply special radiation circumstances according to the radiation type.

3.2.4. Paraffin. As one of the early applicable materials, paraffin is widely used in the nuclear engineering owing to its high fraction of hydrogen elements, just like polyethylene or water to some degree. A paraffin layer wrapped around a radiation source can moderate the high-energy neutrons and transform fast neutrons into thermal neutrons. It is always combined with other substances enriched in neutron absorbing elements, such as paraffin-boric acid neutron shielding blocks [70]. The borated paraffin with low content of boric acid is less obvious for the absorbent of thermal neutrons, while the paraffin with high content cannot attenuate fast neutrons effectively. Neutron shielding performance of borated paraffin is evaluated using ${ }^{241} \mathrm{Am}-\mathrm{Be}$ neutron source and gamma ray transport calculations and compared with that of other applicable materials. The testing results illustrate that borated paraffin can moderate fast neutrons emitted from radiation source more effectively than other materials, as a result improving the collision probability with ${ }^{10} \mathrm{~B}$ nuclei and promoting the absorbent of thermal neutrons. On the other hand, a heavy shield for gamma ray detector has been conducted, and the neutron shielding performance is verified with neutron absorption experiments. 


\section{Conclusions}

With the rapid advancement of nuclear power, storage of spent nuclear fuel and transportation safety have become unavoidable issues. To achieve high density storage of spent nuclear fuel, neutron absorbing materials have become more and more important. At present, the most challenging problem is to consider the disposal of spent nuclear fuel in geological repositories because the half-lives of spent nuclear fuel can last for hundreds of thousands of years. In the short term, the strong radiation beams are beta and gamma ray radiation, while the main radiation for radioactive substances is the natural decay of actinides, which is the most important source of radiation in the longer term. Meanwhile, the mobility of released radionuclides and long-term storage of spent nuclear fuel must be taken into consideration.

More and more requirements for neutron shielding materials have been proposed, including (1) low density and good physical properties, combined with high neutron moderation and thermal neutron absorption cross section; (2) sufficient structure property and intensity; and (3) preparation of different types of components suitable for the assembly. After considering the neutron shielding performance, bearing ability, and mechanical properties of neutron shielding materials at elevated temperature, they have great application potential in the field of nuclear reactors, accelerators, and neutron emitters, especially for the storage rack of spent nuclear fuel. This work can provide a theoretical basis for the optimization design and experimental preparation of novel neutron shielding materials.

\section{Conflicts of Interest}

The authors do not have any commercial or associative interest that represents conflicts of interest in connection with the work submitted.

\section{Acknowledgments}

The authors gratefully acknowledge the financial support from the Fund of Qing Lan Project, Natural Science Foundation of Higher Education Institutions of Jiangsu Province (17KJB430006), and Foundation of Huaian Science and Technology Project (HAB201838, HAP202008, and HAB202069). Finally, the authors thank Dr. Feida Chen, from NUAA, for the help in the tests.

\section{References}

[1] S. Chu and A. Majumdar, "Opportunities and challenges for a sustainable energy future," Nature, vol. 488, no. 8, pp. 294-303, 2012.

[2] N. M. A. Mohamed, "Direct reuse of spent nuclear fuel," Nuclear Engineering and Design, vol. 278, pp. 182-189, 2014.

[3] S. Al Saadi and Y. Yi, "Dry storage of spent nuclear fuel in UAE-economic aspect," Annals of Nuclear Energy, vol. 75, pp. 527-535, 2015.

[4] J. Bruno and R. C. Ewing, "Spent nuclear fuel," Elements, vol. 2, no. 6, pp. 343-349, 2006.
[5] A. M. Sukegawa, Y. Anayama, and K. Okuno, "Flexible heat resistant neutron shielding resin," Journal of Nuclear Materials, vol. 417, pp. 850-853, 2011.

[6] G. Ackland, "Controlling radiation damage," Science, vol. 327, no. 3, pp. 1587-1588, 2010.

[7] X. M. Bai, A. F. Voter, R. G. Hoagland et al., "Efficient annealing of radiation damage near grain boundaries via interstitial emission," Science, vol. 327, no. 5973, pp. 1631-1634, 2010.

[8] D. A. Moreno, B. Molina, C. Ranninger, F. Montero, and J. Izquierdo, "Microstructural characterization and pitting corrosion behavior of UNS S30466 borated stainless steel," Corrosion, vol. 60, no. 6, pp. 573-583, 2004.

[9] D. V. Fix, J. C. Estill, L. L. Wong, and R. B. Rebak, "General and localized corrosion of austenitic and borated stainless steels in simulated concentrated ground waters," in Proceedings of the ASME/JSME 2004 Pressure Vessels and Piping Conference, San Diego, CA, USA, July 2004.

[10] S. E. Soliman, D. L. Youchison, and T. A. Balliett, "Neutron effects on borated stainless steel," Nuclear Technology, vol. 96, no. 3, pp. 346-352, 1991.

[11] M. Bastürk, J. Arztmann, W. Jerlich et al., "Analysis of neutron attenuation in boron-alloyed stainless steel with neutron radiography and JEN-3 gauge," Journal of Nuclear Materials, vol. 341, pp. 189-200, 2005.

[12] C. V. Robino and M. J. Cieslak, "High-temperature metallurgy of advanced borated stainless steels," Metallurgical and Materials Transactions A, vol. 26, no. 7, pp. 1673-1685, 1995.

[13] T. D. Park, K. K. Baek, and D. S. Kim, "PWHT effect on the mechanical properties of borated stainless steel GTA weldments for nuclear shield," Metals and Materials, vol. 3, no. 1, pp. 46-50, 1997.

[14] J. B. Wierschke, Evaluation of Aluminum-Boron Carbide Neutron Absorbing Materials for Interim Storage of Used Nuclear Fuel, University of Michigan, Ann Arbor, MI, USA, 2015.

[15] H. S. Chen, W. X. Wang, Y. L. Li et al., "The design, microstructure and tensile properties of $\mathrm{B}_{4} \mathrm{C}$ particulate reinforced $6061 \mathrm{Al}$ neutron absorber composites," Journal of Alloys and Compounds, vol. 632, pp. 23-29, 2015.

[16] P. Zhang, Y. Li, and W. Wang, "The design, fabrication and properties of $\mathrm{B}_{4} \mathrm{C} / \mathrm{Al}$ neutron absorbers," Journal of Nuclear Materials, vol. 437, no. 1-3, pp. 350-358, 2013.

[17] H. S. Chen, W. X. Wan g, Y. L. Li et al., "The design, microstructure and mechanical properties of B4C/6061 Al neutron absorber composites fabricated by SPS," Materials and Design, vol. 94, pp. 360-367, 2016.

[18] B. Manjunatha, H. B. Niranjan, and K. G. Satyanarayan, "Effect of mechanical and thermal loading on boron carbide particles reinforced Al-6061 alloy," Materials Science \& Engineering A, vol. 632, pp. 147-155, 2015.

[19] Z. G. Xu, L. T. Jiang, Q. Zhang, J. Qiao, D. Gong, and $\mathrm{G}$. $\mathrm{H}$. Wu, "The design of a novel neutron shielding $\mathrm{B} 4 \mathrm{C} / \mathrm{Al}$ composite containing Gd," Materials and Design, vol. 111, pp. 375-381, 2016.

[20] T. Kobayashi, K. Yoshid, and T. Yano, "Microstructure, mechanical and thermal properties of B4C/CNT composites with Al additive," Journal of Nuclear Materials, vol. 440, pp. 524-529, 2013.

[21] K. Pyo So, D. Chen, A. Kushim et al., "Dispersion of carbon nanotubes in aluminum improves radiation resistance," Nano Energy, vol. 22, pp. 319-327, 2016. 
[22] F. Zhang, X. Wang, J. B. Wierschke, and L. Wang, "Helium bubble evolution in ion irradiated $\mathrm{Al} / \mathrm{B}_{4} \mathrm{C}$ metal matrix composite," Scripta Materialia, vol. 109, pp. 28-33, 2015.

[23] J. Zheng, Q. Li, W. Liu et al., "Microstructure evolution of 15 wt.\% boron carbide/aluminum composites during liquidstirring process," Journal of Composite Materials, pp. 1-10, 2016.

[24] Y. J. Kim, J. W. Jang, D. W. Lee, and S. Yi, "Porosity effects of a Fe-based amorphous/nanocrystals coating prepared by a commercial high velocity oxy-fuel process on cavitation erosion behaviors," Metals and Materials International, vol. 21, no. 4, pp. 673-677, 2015.

[25] B. T. Jang, S. S. Kim, and S. Yi, "Wear behaviors of a Fe-based amorphous alloy in ambient atmosphere and in distilled water," Metals and Materials International, vol. 20, no. 1, pp. 55-61, 2014.

[26] J. C. Farmer, J.-S. Choi, C.-K. Saw et al., "Corrosion resistance of amorphous $\quad \mathrm{Fe}_{49.7} \mathrm{Cr}_{17.7} \mathrm{Mn}_{1.9} \quad \mathrm{Mo}_{7.4} \mathrm{~W}_{1.6} \mathrm{~B}_{15.2} \mathrm{C}_{3.8} \mathrm{Si}_{2.4}$ coating: a new criticality control material," Journal of Nuclear Technology, vol. 161, no. 2, pp. 169-189, 2008.

[27] J. Moon and S. Yi, "Mechanical properties and thermal neutron shielding efficiency of high $\mathrm{B}$ amorphous ribbons in the Fe-B-Mo-Cr system," Metals and Materials International, vol. 22, no. 5, pp. 825-830, 2016.

[28] S. L. Wang, H. X. Li, X. F. Zhang, and S. Yi, "Effects of Cr contents in Fe-based bulk metallic glasses on the glass forming ability and the corrosion resistance," Materials Chemistry and Physics, vol. 113, no. 2-3, pp. 878-883, 2009.

[29] S. Pang, T. Zhang, K. Asami, and A. Inoue, "Effects of chromium on the glass formation and corrosion behavior of bulk glassy Fe-Cr-Mo-C-B alloys," Materials Transactions, vol. 43, no. 8, pp. 2137-2142, 2002.

[30] Electric Power Research Institute, Handbook of Neutron Absorber Materials for Spent Nuclear Fuel Transportation and Storage Applications, EPRI, Washington, DC, USA, 2009.

[31] D. W. Glasgow, D. E. Velkley, J. D. Brandenberger, M. T. McEllistrem, H. J. Hennecke, and D. V. Breitenbecher, "Shielding for fast neutron scattering experiments of high sensitivity," Nuclear Instruments \& Methods, vol. 114, no. 3, pp. 521-534, 1974.

[32] S. Joly, J. Voignier, G. Grenier, D. M. Drake, and L. Nilsson, "Measurement of fast neutron capture cross sections using a NaI spectrometer," Nuclear Instruments \& Methods, vol. 153, no. 2-3, pp. 493-501, 1978.

[33] V. D. Svikis, "Dense lithium fluoride for gamma-ray-free neutron shielding," Nuclear Instruments and Methods, vol. 25, no. 1, pp. 93-105, 1964.

[34] S. Nambiar, T. John, and W. Yeow, "Polymer-composite materials for radiation protection," Applied Materials \& Interfaces, vol. 4, no. 11, pp. 5717-5726, 2012.

[35] J. Kim, B.-C. Lee, Y. R. Uhm, and W. H. Miller, "Enhancement of thermal neutron attenuation of nano-B4C, -BN dispersed neutron shielding polymer nanocomposites," Journal of Nuclear Materials, vol. 453, pp. 48-53, 2014.

[36] J. Jun, J. Kim, Y. Bae, and S. S. Young, "Enhancement of dispersion and adhesion of B4C particles in epoxy resin using direct ultrasonic excitation," Journal of Nuclear Materials, vol. 416, pp. 293-297, 2011.

[37] L. Bian, J. Xiao, and J. Zeng, "Effects of thermal treatment on the mechanical properties of poly ( $p$-phenylene benzobisoxazole) fiber reinforced phenolic resin composite materials," Materials and Design, vol. 54, pp. 230-235, 2014.

[38] C. Kizilkaya, Y. Mülazim, M. V. Kahraman et al., "Synthesis and characterization of polyimide/hexagonal boron nitride composite," Journal of Applied Polymer Science, vol. 214, no. 1, pp. 706-712, 2012.

[39] T. Özdemir, I. K. Akbay, H. Uzun, and I. A. Reyhancan, "Neutron shielding of EPDM rubber with boric acid: mechanical, thermal properties and neutron absorption tests," Progress in Nuclear Energy, vol. 89, pp. 102-109, 2016.

[40] K. Ueki, A. Ohashi, N. Nariyama et al., "Systematic evaluation of neutron shielding effects for materials," Nuclear Science \& Engineering, vol. 124, no. 3, pp. 455-464, 1996.

[41] K. Okuno, "Neutron shielding material based on colemanite and epoxy resin," Radiation Protection Dosimetry, vol. 115, no. 1-4, pp. 258-261, 2005.

[42] A. Morioka, S. Sakurai, K. Okuno et al., "Development of $300^{\circ} \mathrm{C}$ heat resistant boron-loaded resin for neutron shielding," Journal of Nuclear Materials, vol. 367, pp. 1085-1089, 2012.

[43] T. Korkut, A. Karabulut, G. Budak et al., "Investigation of neutron shielding properties depending on number of boron atoms for colemanite, ulexite and tincal ores by experiments and FLUKA Monte Carlo simulations," Applied Radiation and Isotopes, vol. 70, pp. 341-345, 2012.

[44] G. Samuel, Sourcebook on Atomic Energy, Van Nostrand Reinhold Company, New York, NY, USA, 3rd edition, 1967.

[45] Y. Huang, W. Zhang, L. Liang et al., "A "Sandwich" type of neutron shielding composite filled with boron carbide reinforced by carbon fiber," Chemical Engineering Journal, vol. 220, pp. 143-150, 2013.

[46] C. Harrison, S. Weaver, C. Bertelsen, E. Burgett, N. Hertel, and E. Grulke, "Polyethylene/boron nitride composites for space radiation shielding," Journal of Applied Polymer Science, vol. 109, pp. 2529-2538, 2008.

[47] Z. Soltani, A. Beigzadeh, F. Ziaie et al., "Effect of particle size and percentages of Boron carbide on the thermal neutron radiation shielding properties of $\mathrm{HDPE} / \mathrm{B}_{4} \mathrm{C}$ composite: experimental and simulation studies," Radiation Physics \& Chemistry, pp. 182-187, 2016.

[48] T. Yasin and M. N. Khan, "High density polyethylene/boron carbide composites for neutron shielding," e-Polymers, vol. 8, no. 1, pp. 670-676, 2008.

[49] H. Chai, X. Tang, M. Ni et al., "Preparation and properties of flexible flame-retardant neutron shielding material based on methyl vinyl silicone rubber," Journal of Nuclear Materials, vol. 464, pp. 210-215, 2015.

[50] A. C. Moloney, H. H. Kausch, T. Kaiser, and H. R. Beer, "Parameters determining the strength and toughness of particulate filled epoxide resins," Journal of Materials Science, vol. 22, no. 2, pp. 381-393, 1987.

[51] S. Ahmed and F. R. Jones, "A review of particulate reinforcement theories for polymer composites," Journal of Materials Science, vol. 25, no. 12, pp. 4933-4942, 1990.

[52] M. K. Lee, J. K. Lee, J. W. Kim, and G. J. Lee, "Properties of $\mathrm{B}_{4} \mathrm{C}-\mathrm{PbO}-\mathrm{Al}(\mathrm{OH})_{3}$-epoxy nanocomposite prepared by ultrasonic dispersion approach for high temperature neutron shields," Journal of Nuclear Materials, vol. 445, pp. 63-71, 2014.

[53] B. Aygün, T. Korkut, and A. Karabulut, "Production and neutron irradiation tests on a new epoxy/molybdenum composite," International Journal of Polymer Analysis \& Characterization, vol. 20, no. 4, pp. 323-329, 2015.

[54] Y. Mulazim, C. Kizılkaya, and M. V. Kahraman, "Thermal and neutron shielding properties of ${ }^{10} \mathrm{~B}_{2} \mathrm{O}_{3} /$ polyimide hybrid materials," Polymer Bulletin, vol. 67, no. 9, pp. 1741-1750, 2011. 
[55] M.-H. Tsai, I.-H. Tseng, J.-C. Chiang, and J.-J. Li, "Flexible polyimide films hybrid with functionalized boron nitride and graphene oxide simultaneously to improve thermal conduction and dimensional stability," Applied Materials \& Interfaces, vol. 6, no. 11, pp. 8639-8645, 2014.

[56] C. Kizilkaya, Y. Mülazim, M. V. Kahraman, N. K. Apohan, and A. Güngör, "Synthesis and characterization of polyimide/ hexagonal boron nitride composite," Journal of Applied Polymer Science, vol. 4, no. 1, pp. 706-712, 2012.

[57] X. L. Fu, X. B. Tang, Y. B. Hu, H. G. Li, and J. Tao, "Effect of different lay-ups on the microstructure, mechanical properties and neutron transmission of neutron shielding fibre metal laminates," Journal of Nuclear Materials, vol. 475, no. 4, pp. 227-236, 2016.

[58] T. Özdemir, A. Güngör, and İ.A. Reyhancan, "Flexible neutron shielding composite material of EPDM rubber with boron trioxide: mechanical, thermal investigations and neutron shielding tests," Radiation Physics and Chemistry, vol. 131, pp. 7-12, 2017.

[59] T. Özdemir, "Monte Carlo simulations of radioactive waste embedded into EPDM and effect of lead filler," Radiation Physics and Chemistry, vol. 98, no. 3, pp. 150-154, 2014.

[60] B.-S. Shin, D.-K. Seo, H.-B. Kim et al., "A study of the thermal and mechanical properties of electron beam irradiated HDPE/ EPDM blends in the presence of triallyl cyanurate," Journal of Industrial and Engineering Chemistry, vol. 18, no. 1, pp. 526-531, 2012.

[61] Y. Abdullah, M. R. Yusof, A. Muhamad, Z. Samsu, and N. E. Abdullah, "Cement-boron carbide concrete as radiation shielding material," Journal of Nuclear and Related Technologies, vol. 7, no. 2, pp. 74-79, 2010.

[62] C. Sivathanu Pillai, A. R. Santhakumar, S. Chandrasekaran et al., "Effect of heat treatment on neutron attenuation characteristics of high density concretes (HDC)," Progress in Nuclear Energy, vol. 93, pp. 76-83, 2016.

[63] A. M. Badiea, B. G. Mohammed, and A. Albadran Firas, "Glass-polymer-concrete composite and its mechanical, chemical and thermal properties," British Journal of Applied Science \& Technology, vol. 16, no. 3, pp. 1-8, 2016.

[64] Y. Abdullah, M. Reusmaazran Yusof, A. Muhamad et al., "Cement-boron carbide concrete as radiation shielding material," Journal of Nuclear and Related Technologies, vol. 7, no. 2, pp. 74-79, 2010.

[65] E. Gallego, A. Lorente, and H. R. Vega-Carrillo, “Testing of a high-density concrete as neutron shielding material," Nuclear Technology, vol. 168, no. 2, pp. 399-404, 2009.

[66] E. Yılmaz, H. Baltas, E. Kırıs, İ. Ustabas, U. Cevikc, and A. M. EI-Khayatt, "Gamma ray and neutron shielding properties of some concrete materials," Annals of Nuclear Energy, vol. 38, no. 10, pp. 2204-2212, 2011.

[67] V. P. Singh, N. M. Badiger, N. Chanthima, and J. Kaewkhao, "Evaluation of gamma-ray exposure buildup factors and neutron shielding for bismuth borosilicate glasses," Radiation Physics and Chemistry, vol. 98, no. 5, pp. 14-21, 2014.

[68] N. A. Elalaily, E. M. Abou-Hussien, and E. A. Saad, "Bismuth silicate glass containing heavy metal oxide as a promising radiation shielding material," Radiation Effects and Defects in Solids, vol. 171, no. 10, pp. 840-854, 2016.

[69] V. P. Singh, N. M. Badiger, and J. Kaewkhao, "Radiation shielding competence of silicate and borate heavy metal oxide glasses: comparative study," Journal of Non-crystalline Solids, vol. 404, no. 11, pp. 167-173, 2014.

[70] M. Igashira, H. Kitazawa, and N. Yamamuro, "A heavy shield for the gamma-ray detector used in fast neutron experiments," Nuclear Instruments and Methods in Physics Research Section A: Accelerators, Spectrometers, Detectors and Associated Equipment, vol. 245, no. 2-3, pp. 432-437, 1986. 